\title{
Cleaning Efficiency of XP-endo Finisher File in Comparison with Sonic and Ultrasonic Irrigation Systems (An In Vitro Study)
}

\author{
Mohanad Ghazi Azzawi ${ }^{1}$, Jamal Aziz Mehdi² \\ ${ }^{1}$ (Department of Conservative Dentistry, College of Dentistry, Al-Mustansiriya University, Iraq) \\ ${ }^{2}$ (Department of Conservative Dentistry, College of Dentistry, Al-Mustansiriya University, Iraq)
}

\begin{abstract}
Cleaning and shaping of root canals is a crucial step in endodontic treatments. Irrigation allows removal of residual tissues in the canal that cannot be cleaned by instrumentation alone. This study evaluates and compares the efficiency of XP-endo Finisher (XPF), EndoActivator (EA) and Passive Ultrasonic Irrigation (PUI) in removing dentin debris and to compare percentage of remaining dentin debris for each irrigation system.

Sixty extracted upper molar teeth with straight palatal canals were used in this study. Canals were prepared with ProTaper NEXT files to size X4 with $1 \mathrm{ml} 2.0 \% \mathrm{NaOCl}$ irrigation between files. Roots were distributed into three groups of twenty samples and irrigated with $1 \mathrm{ml} 2.0 \% \mathrm{NaOCl}$ which was activated for 60 seconds using three irrigation systems; group one, XPF; group two, EA; and group three, PUI, then the groups were rinsed with $5 \mathrm{ml}$ $2.0 \% \mathrm{NaOCl}$. Roots were split longitudinally, photographed digitally, images transferred to a computer, and percentage of remaining dentin debris at apical, middle and coronal levels was calculated. Data were analyzed statistically by ANOVA and LSD at 1\% and 5\% significant levels. Results showed that cleaning with XPF or PUI resulted in significantly cleaner canals $(P<0.01)$ than EA at all canal levels. XPF resulted in cleaner canals than $P U I$ at all levels, but with insignificant statistical difference $(P>0.05)$. Apical level of all canals showed greater amount of dentin debris $(P<0.01)$ compared to middle and coronal levels, regardless of irrigation system used.
\end{abstract}

Keywords: EndoActivator, Irrigation, Passive Ultrasonic Irrigation, XP-endo Finisher.

\section{Introduction}

The goal of endodontic therapy is the removal of all vital or necrotic tissues, microorganisms, and microbial by-products from the root canal system. The root canal system is highly complex and variable and has limited our ability to clean and disinfect it predictably. Shaping of root canals is performed almost entirely by using hand and rotary instrumentation techniques ${ }^{[1]}$.

Peters et al., using micro computed tomography scans before and after mechanical instrumentation found that, regardless of the instrumentation technique, $35 \%$ or more of the root canal surfaces (including canal fins, isthmuses, and cul-de-sacs) remained uninstrumented ${ }^{[2]}$. Thus, instrumentation alone does not fully prepare the root canal system for obturation, and disinfection is the key to the augmentation of instrumentation process and optimization of the obturation process ${ }^{[3]}$.

Disinfection is comprised of the removal of the tissue remnants and the associated bacteria in the root canal system through flushing with irrigating solution. The key is to remove as much tissue remnant as possible and the more thorough the process of irrigation, the lower the remaining level of bacteria ${ }^{[4]}$.

Optimal irrigation is based on the use of a combination of two or more irrigating solutions, in a specific sequence, to obtain the goals of effective and safe irrigation predictably. Traditionally, delivery of the irrigant solutions into the root canal system have been done using plastic syringes and metal needles of different sizes and tip designs. However, research and clinical experience have shown, that this classic approach typically results in irrigation that is ineffective, especially in areas such as fins, anastomoses, and the most apical region of the root canal system. Therefore, many of the irrigation solutions have been modified chemically and many mechanical devices have been developed for the improvement of the effectiveness and penetration of irrigation ${ }^{[5]}$.

In spite of the recent advances in irrigation systems, it is still not possible to remove all debris from the root canal systems. Inadequate canal debridement can lead to a decrease in endodontic success ${ }^{\left[{ }^{[}\right.}$. For this reason, different irrigation systems were used in this study and the cleaning efficiency of each system was evaluated and compared to find which system is more preferable for the cleaning of root canals.

\section{Materials and Methods}

Sixty freshly extracted human maxillary molar teeth with straight palatal root canals collected from different specialized dental centers were used in this study.

Immediately after extraction; bone, calculus, stains and soft tissues on the tooth surface were removed manually by the use of a cumine ${ }^{[7]}$, disinfected with $3.0 \% \mathrm{NaOCl}$ solution for 30 minutes ${ }^{[8]}$, followed by washing with tap water. The teeth were then stored in a plastic container containing $0.1 \%$ thymol solution ${ }^{[7]}$. 
With the aid of a digital caliper and a permanent red marker, the length of the palatal roots was standardized to $11 \mathrm{~mm}$ from the anatomic apex. The teeth were then mounted on a bench vice, and a double-faced diamond disc mounted on a straight handpiece was used, under water coolant, for sectioning the palatal root perpendicular to the long axis of the root according to the drawn line.

The pulpal tissues were removed using barbed broaches, and the exact location of the apical foramen and the patency of the canals were verified by the insertion of a \#10 stainless steel K-file and advanced slowly until it is visualized at the apical foramen by the aid of a 20x magnifier. The silicon stopper was adjusted, the file was removed and measured, and the correct working length was established by subtracting $1 \mathrm{~mm}$ from the above measurement ${ }^{[9]}$. To facilitate handling of the samples during the subsequent steps, the samples were embedded, except for the coronal 3 millimeters, in surgical tubes filled with silicon rubber base impression material of putty consistency and mounted on a bench vice to establish a standardized position during the following steps.

All the canals were prepared with ProTaper NEXT rotary system (Dentsply Maillefer, Ballaigues, Switzerland) with the instrumentation sequence beginning with the X1 file, followed by X2, X3 and reaching a final size of X4.

The roots were then divided into three groups of 20 samples each.

- Group 1: the canals were cleaned with the XP-endo Finisher (FKG Dentaire, La Chaux-de-Fonds, Switzerland) (Fig.1). After working length adjustment to $10 \mathrm{~mm}$ with the provided tube, the Finisher was cooled down with ethyl chloride spray while it is inside the tube. After irrigating the canal with $1.0 \mathrm{ml} 2.0 \% \mathrm{NaOCl}$, the Finisher was removed from the tube and activated while its tip was inside the canal. The Finisher was activated for 60 seconds inside the canal using gentle $7-8 \mathrm{~mm}$ lengthwise movements to contact the full length of the canal.

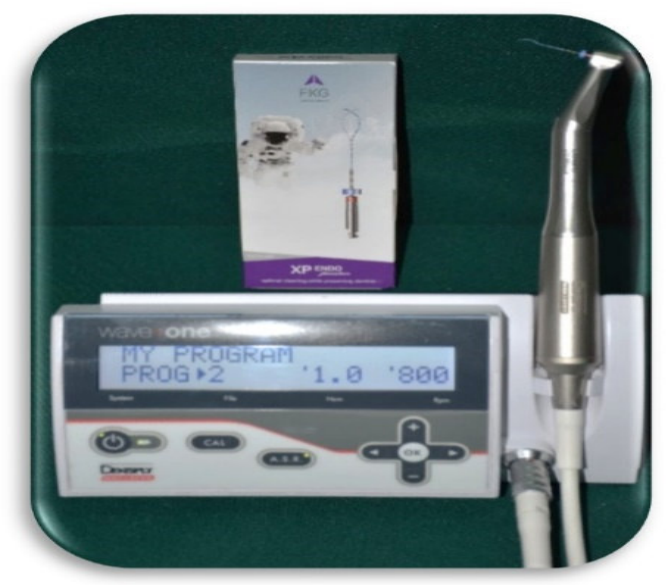

Figure 1: XP-endo finisher.

- Group2: the canals were cleaned with the EndoActivator sonic irrigation system (Dentsply Tulsa Dental Specialties, Tulsa, OK, USA) (Fig.2) using the medium-size polymer tip (25/.04). After irrigating the canal with $1.0 \mathrm{ml} 2.0 \% \mathrm{NaOCl}$, the tip was fitted passively inside the canal, $2 \mathrm{~mm}$ shorter than the working length, and activated at 10,000 cycles/minute for 60 seconds with pumping action in short $2-3 \mathrm{~mm}$ vertical strokes.

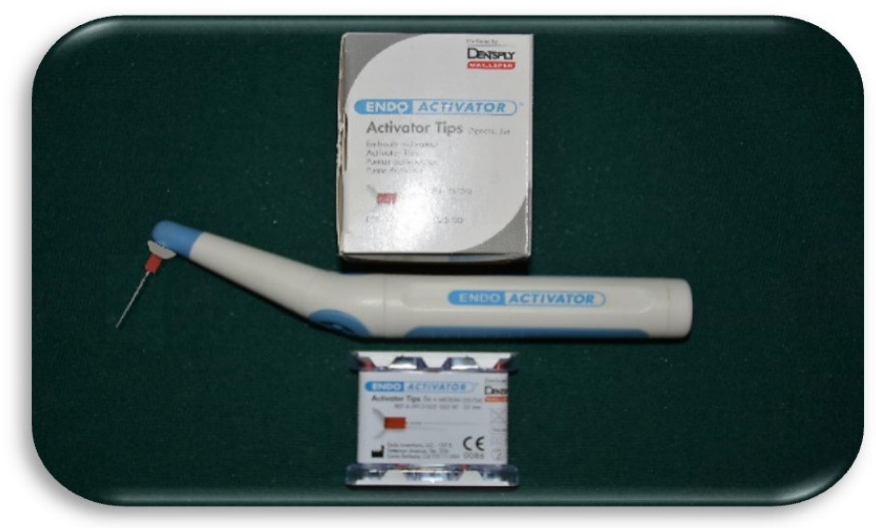

Figure 2: EndoActivator system. 
- Group3: The instrumented roots were subjected to passive ultrasonic activation using the Varios 570 iPiezo Engine (Nakanishi Inc., Tochigi, Japan) (Fig.3) with stainless steel \#25 ultrasonic file, $1 \mathrm{~mm}$ shorter than the working length and passively moving inside the root canal. For this group, the $1.0 \mathrm{ml}$ of irrigant solution to be activated was divided into 3 equal parts, with each part delivered and ultrasonically activated for 20 seconds, for a total period of 60 seconds, for better removal of debris than continuous irrigation ${ }^{[10]}$.

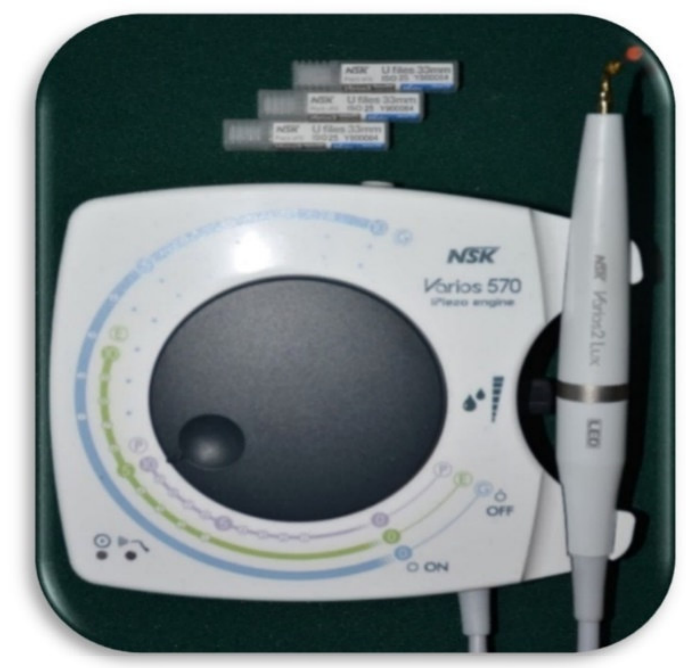

Figure 3: NSK Varios 570 iPiezo engine.

After cleaning the canals for each group, the canals received a final rinse of $5.0 \mathrm{ml} 2.0 \% \mathrm{NaOCl}$, followed by dryness with ProTaper NEXT paper points size X4. Then the canals were sealed coronally with self-cure glass ionomer cement as a temporary filling to prevent the entry of debris during sectioning and prevent contamination of the root canal space ${ }^{[11-13]}$.

The roots were then removed from their tubes and a marker was used to draw guiding lines longitudinally on the buccal and palatal sides. The roots were then mounted on the bench vice and longitudinally grooved buccopalatally on the previously marked lines with a diamond disc mounted on a low speed straight handpiece under water cooling, preserving the inner shelf of dentin surrounding the canal. The grooves were then cleaned from any remaining debris with a short blast of air. Then the roots were split by placing a surgical blade \#15 in the groove and striking the blade gently with a small mallet ${ }^{[14]}$. The longitudinal section of each root with $\leq 180^{\circ}$ of the canal circumference was selected for the study. The sections with $>180^{\circ}$ of canal circumference would possibly interfere with the total canal visualization during photography ${ }^{[7,9,14-16]}$. Teeth showing that the groove had penetrated the canal were discarded and replaced ${ }^{[17]}$.

Images of the split roots were taken using a 24-megapixels Nikon D7100 professional digital SLR camera using a macro lens at 1:1 setting with electronic macro flash and saved to a notebook computer with maximum resolution of $6000 \times 4000$ pixels. The camera system was mounted on a professional tripod in an upside-down orientation, the sectioned roots were placed over a millimeter grid paper under the camera lens, and the distance between the focal plane mark on the camera body and the root section, which was selected according to the optimum focusing without any blurring, remained constant during image capturing of all samples.

The images were opened with Adobe Photoshop CC 2015 and magnified 200 times with the digital zoom tool. The root canal area was divided into equal thirds (apical, middle, coronal) by using superimposing lines. The amount of dentin debris re ma in ing in each canal was traced by using the magnetic lasso tool, and the histogram function of the software reported the total number of pixels occupied by the debris. The outline of the canal was also traced and the histogram function of the software reported the total pixels occupied by the canal. The percentage of remaining dentin debris at each level was calculated using the equation $(1)^{[7,14,15]}$.

Percentage of dentin debris at each level $=\frac{\text { Pixels of dentin debris at each level }}{\text { Total pixels of entire canal area }} \times 100$

The data were collected and statistically analyzed using the IBM Statistical Package for the Social Sciences version 20 (SPSS, Chicago, IL, USA). One-way Analysis of Variance (ANOVA) and Least Significant Difference (LSD) tests were used to determine whether there is a statistical difference between the groups and between the different levels within each group with a significance level of $P<0.05$. 


\section{Results}

The mean percentage of remaining dentin debris in experimental groups is shown in (Table1) and (Fig.4).

Table1: Descriptive statistical analysis for the percentage of dentin debris remaining at the three levels (Apical, Middle, Coronal) for the irrigation systems.

\begin{tabular}{|c|c|c|c|c|c|c|}
\hline Levels & Tested Groups & $\mathrm{n}$ & Minimum \% & Maximum \% & Mean \% & \pm SD \\
\hline \multirow{4}{*}{$\begin{array}{c}\text { Apical } \\
(0-3 \mathrm{~mm})\end{array}$} & XP-endo Finisher & 20 & 1.42 & 2.36 & 1.88 & 0.31 \\
\cline { 2 - 7 } & EndoActivator & 20 & 2.98 & 6.89 & 5.27 & 1.29 \\
\cline { 2 - 7 } & PUI & 20 & 1.52 & 3.27 & 2.33 & 0.49 \\
\hline \multirow{3}{*}{$\begin{array}{c}\text { Middle } \\
(3-6 \mathrm{~mm})\end{array}$} & XP-endo Finisher & 20 & .78 & 1.65 & 1.17 & 0.24 \\
\cline { 2 - 8 } & EndoActivator & 20 & 1.60 & 4.03 & 2.40 & 0.51 \\
\cline { 2 - 8 } & PUI & 20 & .93 & 2.00 & 1.39 & 0.29 \\
\hline \multirow{3}{*}{$\begin{array}{c}\text { Coronal } \\
(6-9 \mathrm{~mm})\end{array}$} & XP-endo Finisher & 20 & .82 & 1.55 & 1.24 & 0.23 \\
\cline { 2 - 8 } & EndoActivator & 20 & 1.44 & 3.68 & 2.57 & 0.62 \\
\cline { 2 - 8 } & PUI & 20 & .91 & 2.09 & 1.50 & 0.30 \\
\hline
\end{tabular}

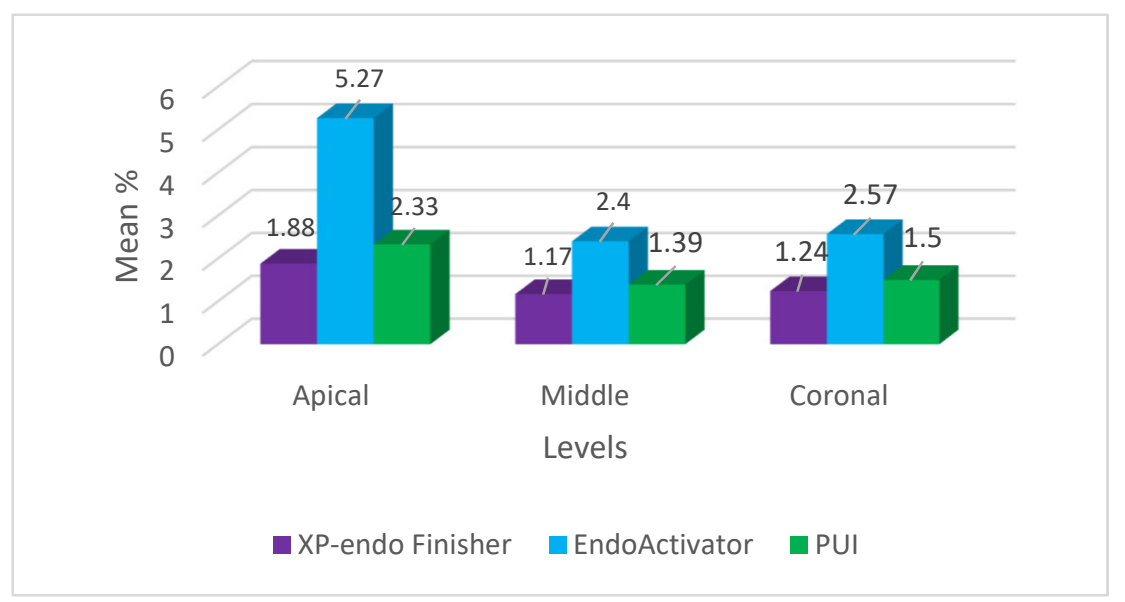

Figure 4: Bar chart showing mean percentage of dentin debris remaining

1. The comparison between the three irrigation systems in removing dentin debris at each level

To compare among the three irrigation systems at each level, ANOVA test was performed to analyze the presence of statistically significant difference for the percentage of remaining dentin debris and the result showed that there are highly significant differences at all regions. Least Significant Difference test (LSD) was performed and the result showed that at the apical, middle and coronal levels, no significant difference $(P>0.05)$ was found between the XPendo Finisher group and the PUI group, while high significant differences $(P<0.01)$ were found between the EndoActivator group and both the XP-endo Finisher and PUI groups.

2. The comparison between the remaining dentin debris at three different levels for each irrigation system For all of the irrigation systems, high significant differences $(P<0.01)$ were found between the apical and middle levels and between the apical and coronal levels, while no significant difference $(P>0.05)$ was found between the middle and coronal levels.

\section{Discussion}

In the presence of infection, one purpose of the mechanical cleaning of the root canal system is the removal of the inner layer of contaminated dentin, by scraping the walls of this anatomical space. However, dentin surfaces may remain untouched after endodontic preparation ${ }^{[1,18]}$, so this disinfection must be complemented by the action 
of irrigating solutions ${ }^{[19,20]}$. Moreover, during instrumentation, there is the production of dentin shavings, which if left in the root canal alongside the remnants of the necrotic tissues and microorganisms, may lead to the perpetuation of infection and generation of an adverse endodontic treatment prognosis ${ }^{[21]}$. It has been demonstrated that a potential side effect of instrumentation is the accumulation of debris, which negatively impact the sealing ability of root canal fillings ${ }^{[\mathbf{1}, 5]}$.

Although conventional irrigation (needle/syringe) has been widely used, several techniques and devices have been proposed to optimize the chemical and mechanical properties and improve the penetration of irrigating solutions; these include the use of syringes associated with modified needles, sonic and ultrasonic devices, and negative pressure irrigation systems ${ }^{[22-24]}$.

In this study, three different irrigation systems were compared for their efficiency in removing dentin debris. The first system was the XP-endo Finisher, the second system was the EndoActivator, which depend on sonic technology for irrigation, and the third system was the NSK Varios ultrasonic irrigation system.

\section{The efficiency of the three irrigation systems at the apical level}

At the apical level, both the XP-endo Finisher and the PUI systems resulted in less dentin debris remaining compared with the EndoActivator system; the XP-endo Finisher showed least amount of dentin debris remaining among all groups but statistically, no significant difference was found between the XP-endo Finisher and the PUI system. Highly significant difference was found between the EndoActivator system and the other groups.

The absence of a statistically significant difference between the XP-endo Finisher and the PUI is in agreement with Leoni et al. ${ }^{[25]}$. This may be explained because of the highly flexible proprietary alloy combined with the small core size and zero taper of the XP-endo Finisher instrument, which allowed it to expand its reach when in rotation ${ }^{[26]}$. This unique property promoted the agitation of the irrigant solution inside the canal, resulting in the disruption and removal of the accumulated hard tissue debris by the final flushing action of the syringe/needle irrigation, similarly to PUI ${ }^{[25]}$.

The reduced cleaning efficiency of the EndoActivator compared with the PUI in this study is supported by the results of Jiang et al. ${ }^{[27]}$. When EndoActivator tip is placed in the apical level, there is a certain amount of dampening that occurs when there is contact with the canal walls. This inhibits the free oscillation of the sonic tip, reducing the efficient streaming of the irrigant. This may explain the results that the ultrasonic activation removed more debris than the sonic activation ${ }^{[14]}$. Those results are in disagreement with Klyn et al. ${ }^{[28]}$ who found no significant differences between sonic and ultrasonic irrigation systems.

The high significant difference in cleaning efficiency of the XP-endo Finisher compared with the EndoActivator system is in disagreement with Elnaghy et al. ${ }^{[29]}$, who found that there is no statistically significant difference between the two systems in debris and smear layer removal. This difference in the result might be explained as the consequence of differences in the methodological design including curved root canal configuration, preparation protocol using BT-RaCe rotary system reaching apical size of 35/.04, irrigant solution (concentration, volume, and flowrate), and the percentage of dentin debris after root canal preparation.

\section{The efficiency of the three irrigation systems at the middle and coronal levels}

At the middle and coronal levels, the XP-endo Finisher resulted in less dentin debris remaining compared with the PUI and the EndoActivator systems. Also, the PUI resulted in less dentin debris compared to the EndoActivator system.

No significant difference was found between the XP-endo Finisher and the PUI group at the middle and coronal levels. These results also coincide with the results of Leoni et al. ${ }^{[25]}$, who also found no significant difference in the cleaning between the two systems, but the PUI system in their study resulted in slightly cleaner canals at those levels than the XP-endo Finisher group, which could be due to some differences in the experimental conditions, including the use of reciprocating files in instrumenting canals with isthmuses, and with no irrigation during the whole instrumentation procedure; these conditions combined allow for the build-up of great amounts of dentin debris. The increased efficiency of the XP-endo Finisher in this study is due to its flexibility allowing it to expand its reach to $6 \mathrm{~mm}$ in diameter or 100 -fold greater than an equivalent-sized file, thus is claimed to allow the mechanical cleaning of the canal in areas previously impossible to reach ${ }^{[26]}$.

The superior cleaning efficiency of the PUI in the middle and coronal regions compared with the EndoActivator is in agreement with Sabins et al. ${ }^{[14]}$, whose study also found a significant difference in cleaning efficiency between the passive ultrasonic irrigation and the passive sonic irrigation. These results could be due to the higher driving frequency of ultrasound in comparison to the sonic devices. Therefore, the flow velocity and the cleaning efficiency are lower for the sonically activated irrigation, resulting in less effective delivery to the root canal extensions ${ }^{[14,30]}$.

The highly significant difference in the cleaning efficiency of the XP-endo Finisher compared to the EndoActivator at the coronal and middle levels are in disagreement with the study of Elnaghy et al. ${ }^{[29]}$. This reduced efficiency of the EndoActivator could be attributed to the oscillation pattern of the sonically activated tip, having a 
node at the attachment point, at which the least oscillation amplitude is located.

\section{The amount of debris among the three levels}

The percentage of dentin debris remaining at the middle levels showed no significant difference with coronal levels, which is supported by the results of Sabins $\boldsymbol{e t}$ al. and Vansan $\boldsymbol{e t} \boldsymbol{a l} .{ }^{[14,31]}$. The percentage of dentin debris remaining at the middle and coronal levels were less than that found at the apical level for all groups, because the apical level is narrower than the middle and coronal levels, so less amount of irrigation can be delivered to this area and also the irregularity and complexity of this area rendering more debris apically ${ }^{[32]}$. These findings are in agreement with

\section{Sabins et al.; Elnaghyet al.; Vansan et al.; Rödig et al.; Kamel and Kataia ${ }^{[14,29,31-33]}$.}

\section{Conclusion}

According to the proposed methodology and based on the findings of this study, the following conclusions could be drawn:

- None of the tested irrigation devices was able to completely remove dentin debris from approximately straight root canals.

- Using the XP-endo Finisher or the passive ultrasonic irrigation (PUI) was more effective than EndoActivator sonic irrigation.

- The apical level showed greater amount of debris than the middle and coronal levels, regardless of the irrigation device used.

\section{References}

[1]. Paqué F, Ganahi D, Peters OA. Effects of root canal preparation on apical geometry assessed bymicro-computed tomography. $\mathrm{J}$ Endod 2009;35:1056-1059.

[2]. Peters OA, Schönenberger K, Laib A. Effects of four Ni-Ti preparation techniques on root canal geometry assessed by micro computed tomography. Int Endod J 2001;34:221-230.

[3]. Gregori MK. Improving endodontic success through use of the EndoVac irrigation system. Endod Pract 2009:17-20.

[4]. Kurtzman GM. Positive versus negative pressure irrigation. Roots 2012;8(1):16-22.

[5]. Haapasalo M, Ya Shen, Wei Qian, Yuan Gao. Irrigation in Endodontics. Dent Clin N Am 2010;54:291-312.

[6]. Siqueira Jr JF. Etiology of root canal treatment failure: why well treated teeth can fail. Int Endod J 2001;34:1-10.

[7]. Alkahtani A, Al Khudhairi TD, Anil S. A comparative study of the debridement efficacy and apical extrusion of dynamic and passive root canal irrigation systems. BMC Oral Health 2014,14:12.

[8]. Aminsobhani M, Ghorbanzadeh A, Dehghan S, Niasar AN, Kharazifard MJ. A comparison of canal preparations by Mtwo and $\mathrm{RaCe}$ rotary files using full sequence versus one rotary file techniques; a cone-beam computed tomography analysis. Saudi Endod J 2014;4(2):70-76.

[9]. Ghoneim WM, Farag AM, Labib AH, Darrag AM. Cleaning efficacy of different root canal preparation systems and irrigation regimens. Tanta Dent J 2014;1-6.

[10]. Van der Sluis LW, Versluis M, Wu MK, Wesselink PR. Passive ultrasonic irrigation of the root canal: a review of the literature. Int Endod J 2007;40:415-426.

[11]. Nielsen BA, Baumgartner CJ. Comparison of the EndoVac system to needle irrigation of root canals. J Endod 2007;33:611-615.

[12]. Howard RK, Kirkpatrick TC, Rutledge RE, Yaccino JM. Comparison of debris removal with three different irrigation techniques. J Endod 2011;37(9):1301-1305.

[13]. Shetty K, Kamath P, Kundabala M, Rao A. Smear layer evaluation after root canal instrumentation with manual and rotary techniques: A scanning electron microscopic study. Int J Adv Res 2014;2(4):447-453.

[14]. Sabins RA, Johnson JD, Hellstein JW. A comparison of the cleaning efficacy of short-term sonic and ultrasonic passive irrigation after hand instrumentation in molar root canals. J Endod 2003;29:674-678.

[15]. Munley PJ, Goodell GG. Comparison of passive ultrasonic debridement between fluted and nonfluted instruments in root canals. J Endod 2007;33:578-580.

[16]. Zamiran S, Jahromi MZ, Fathi MH, Moghaddam G. An in vitro study on cleaning efficiency of Mtwo and BioRaCe rotary nickeltitanium instruments. Health 2013;5:2045-2050.

[17]. Zmener O, Pameijer CH, Serrano SA, Hernandez SR. Cleaning efficacy using two engine-driven systems versus manual instrumentation in curved root canals: A scanning electron microscopic study. Int Endod J 2011;37:1279-1282.

[18]. Wu MK, van der Sluis LWM, Wesselink PR. The capability of two hand instrumentation techniques to remove the inner layer of dentine in oval canals. Int Endod J 2003;36:218-224.

[19]. Byström A, Sundqvist G. The antibacterial action of sodium hypochlorite and EDTA in 60 cases of endodontic therapy. Int Endod J 1985;18:35-40.

[20]. McGurkin-Smith R, Trope M, Caplan D, Sigurdsson A. Reduction of intracanal bacteria using GT rotary instrumentation, $5.25 \%$ $\mathrm{NaOCl}$, EDTA, and $\mathrm{Ca}(\mathrm{OH}) 2$. J Endod 2005;31:359-363.

[21]. Siqueira Jr JF, Rôças IN. Clinical implications and microbiology of bacterial persistence after treatment procedures. J Endod 2008;34:1291-1301.

[22]. Halford A, Ohl CD, Azarpazhooh A, Basrani B, Friedman S, Kishen A. Synergistic effect of micro bubble emulsion and sonic or ultrasonic agitation on endodontic biofilm invitro. J Endod 2012;38:1530-1534.

[23]. Bolles JA, He J, Svoboda KK, Schneiderman E, Glickman GN. Comparison of Vibringe, EndoActivator, and needle irrigation on sealer penetration in extracted human teeth. J Endod 2013;39:708-711.

[24]. Khan S, Niu LN, Eid AA, Looney SW, Didato A, Roberts S, Pashley DH, Tay FR. Periapical pressures developed by non-binding irrigation needles at various irrigation delivery rates. J Endod 2013;39:529-533.

[25]. Leoni GB, Versani MA, Silva-Sousa YT, Bruniera FB, Pecora JD, Sousa-Neto MD. Ex-vivo evaluation of four final irrigation protocols on the removal of hard-tissue debris from the mesial root canal system of mandibular first molars. Int Endod J 2016; AcceptedArticle, DOI:10.1111/iej.12630.

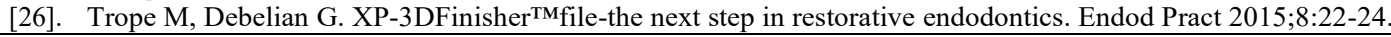


[27]. Jiang LM, Verhaagen B, Versluis M, van der Sluis LW. Evaluation of a sonic device designed to activate irrigant in the root canal. J Endod 2010;36:143-146.

[28]. Klyn SL, Kirkpatrick TC, Rutledge RE. In vitro comparison of debris removal of the EndoActivator system, the F File, ultrasonic irrigation and $\mathrm{NaOCl}$ irrigation alone after hand-rotary instrumentation in human mandibular molars. J Endod 2010;36:13671371.

[29]. Elnaghy AM, Mandorah A, Elsaka SE. Effectiveness of XP-endo Finisher, EndoActivator, and file agitation on debris and smear layer removal in curved root canals: a comparative study. Odontology 2016.DOI:10.1007/s10266-016-0251-8.

[30]. Ahmad M, PittFord TR, Crum LA, Walton AJ. Ultrasonic debridement of root canals: acoustic cavitation and its relevance. J Endod 1988;14:486-493.

[31]. Vansan LP, Pecora JD, Costa WF, Maia Campos G. Effects of various irrigating solutions on the cleaning of the root canal with ultrasonic instrumentation. BrazDentJ 1990;1(1):37-44.

[32]. Rödig T, Döllmann S, Konietschke F, Drebenstedt S, Hülsmann M. Effectiveness of different irrigant agitation techniques on debris and smear layer removal in curved root canals: A scanning electron microscopy study. J Endod 2010;36:1983-1987.

[33]. Kamel WH, Kataia EM. Comparison of the efficacy of SmearClear with and without a canal brush in smear layer and debris removal from instrumented root canal using WaveOne versus ProTaper: a scanning electron microscopic study. J Endod 2014;40(3):446-450. 